\title{
Prevention and follow-up in thromboembolic ischemic stroke: do we need to think out of the box?
}

\author{
Albe C. Swanepoel ${ }^{1}$, Etheresia Pretorius ${ }^{1}$ \\ ${ }^{1}$ Department of Physiology, School of Medicine, Faculty of Health Sciences, University of Pretoria, South Africa
}

\section{${ }^{*}$ Corresponding Authors \\ CORRESPONDING AUTHORS}

Albe C Swanepoel

Department of Physiology, Faculty of Health Sciences, University of Pretoria

Private Bag x323, ARCADIA, 0007

SOUTH AFRICA

Albe.swanepoel@up.ac.za

\section{Etheresia Pretorius}

Department of Physiology, Faculty of Health Sciences, University of Pretoria

Private Bag x323, ARCADIA, 0007

SOUTH AFRICA

resia.pretorius@up.ac.za

Tel: (+27)12 4202864

\section{ABSTRACT}

Stroke is one of the most debilitating thrombotic diseases, and world-wide it is estimated that by, 203023 million people will be affected. Except for the impact on the individual families, the world economy is also affected adversely. Although the medical treatment and knowledge of stroke are both increasing and well-researched, we still do not see a light in the tunnel. Currently various diagnostic tests are employed to determine the specific type of ischemic stroke as classified by the TOAST criteria. However, these tests are done after the stroke has occurred and therefore only contribute to the unquestionably crucial aspect of treating that particular stroke patient, but it does not improve prevention of future events. Prevention strategies regarding first-time stroke need urgent attention given the alarming present and future incidence of stroke. Therefore, here we discuss the importance of stroke prevention and suggest a more inclusive, perhaps "new" comprehensive approach for prestroke screening. Ultrastructural tests, particularly scanning electron microscopy, provide an innovative and novel advance in preventative and individualized patient-centered 
precision medicine. This precise technique when used in combination with well-established methods, as well as viscoelastic methods like thromboelastography (TEG), as a screening tool to prevent stroke can ultimately alleviate the financial and economical burden of stroke and also improve quality of life. Although we appreciate the fact that this suggestion might be difficult to accept by clinicians, a bold new approach is needed to address this pandemic we call stroke.

KEYWORDS: Thromboembolic ischemic stroke; scanning electron microscopy, comprehensive approach

\section{Introduction}

Stroke, one of the most debilitating conditions, mainly results from ischemia due to occlusion or stenosis of the blood vessel (approximately $87 \%$ of stroke cases) while a few cases are attributed to haemorrhage where a blood vessel ruptures or leaks[1, 2]. Annually 17 million people worldwide are affect by stroke and in 2010 alone there were 33 million stroke survivors with many cases associated with disability [3]. About 800000 of these cases occur in the USA [4], with primary stroke being the major contributor (around 600000 cases) [5]. In the United States alone every 40 seconds someone suffers a stroke, while, on average, a person dies of a stroke every 4 minutes [4]. Furthermore, it is envisaged that by 2030 an additional 3.4 million people will suffer a stroke compared to 2012 [6]. A global estimate for 2030 is 23 million people suffering a primary stroke with almost 7.8 million deaths as result of stroke $[7,8]$.

A subsequent increase in stroke survivors (an estimated 15.2 million individuals), ascribed to the increase in the aging population, accompanied by increased strain on health- and socialcare structures, is thus inevitable [6]. Although there are so many stroke survivors, survival is a double-edged sword, as it is also considered to be the foremost cause of chronic disability [5]. Almost a third of stroke survivors are permanently disabled and one fifth require institutional care after 3 months [9]. Almost half of stroke cases in the elderly result in cognitive deficits while a third affect the independence of these individuals to perform daily activities [10]. Post-stroke quality of life is therefore (mostly) synonymous with functional impairment.

500 people per 100000 are currently living with post-stroke consequences [11] and it is suggested that by 2030 , stroke-related disability will rank as the fourth leading cause of disability-adjusted life years, relating to the years lost due to illness [12]. It not only alters the 
lives of those who suffered the stroke, and who most likely are disabled by it, it also influences the lives of the victim's family and loved ones as well as caregivers [13].

The financial implications are currently believed to have the following global impact:

- Stroke consumes roughly $2-4 \%$ of total global health-care expenditure [11].

- Estimations for 2030 suggest that direct medical stroke-related expenses will be triple the current value and is estimated to be $\$ 184.13$ billion.

- Annual cost as a result of lost productivity, will most probably increase with $68 \%$, to approximately $\$ 56.54$ billion [6].

- The total annual cost in billion $€ 2010$ of stroke in Europe is about 64.1 [14].

- In the USA it is the section of the working population with the most employment experience (age 45-64 years) that are expected to be hit the hardest with increased stroke incidence of $5.1 \%$ by 2030 [6].

In the current paper we discuss the importance of stroke prevention and suggest a more inclusive, perhaps "new" comprehensive approach for pre-stroke screening. Figure 1 supplies the summary of this paper.

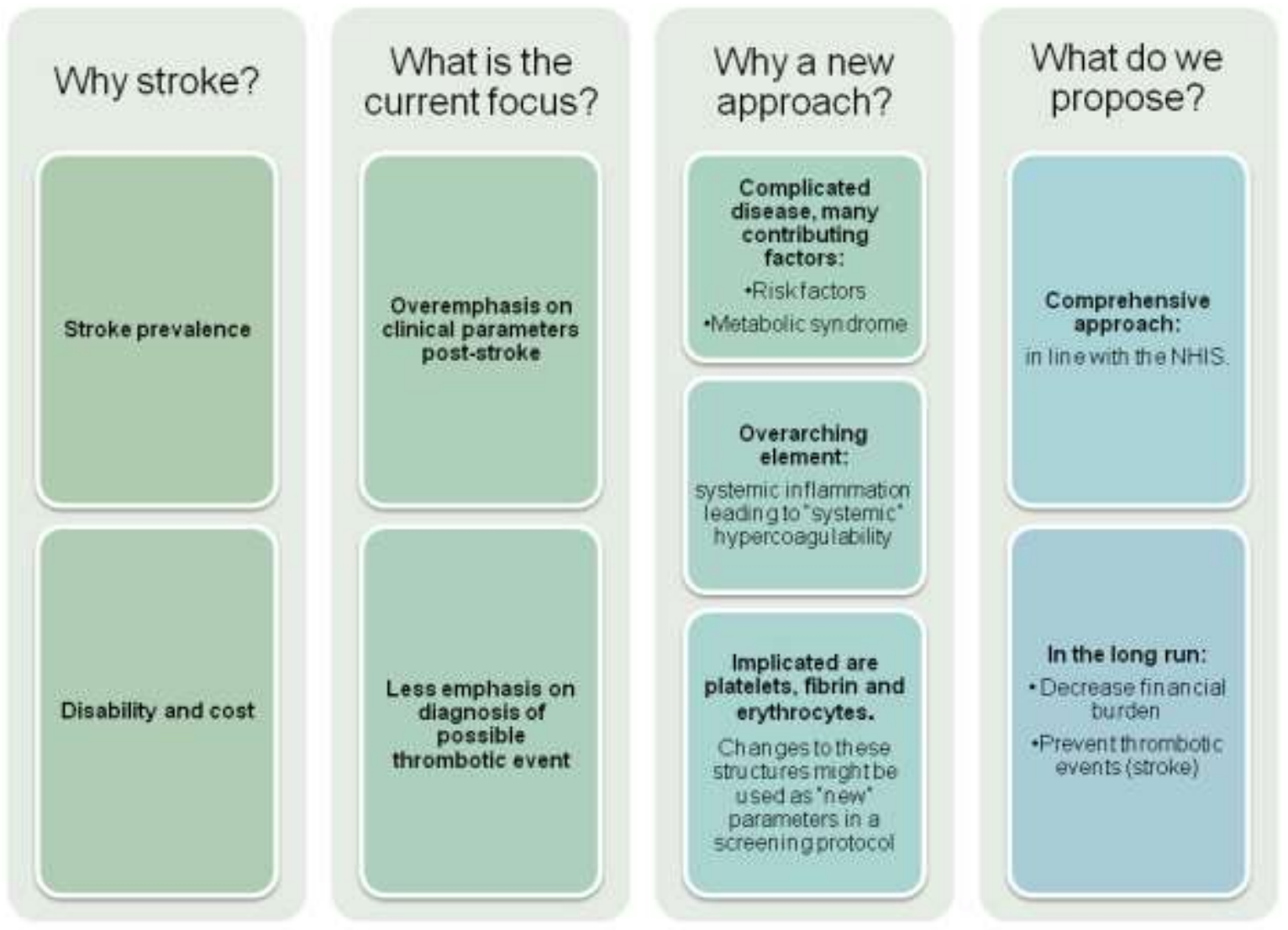

Figure 1. Synopsis of the prevention of stroke and a new comprehensive approach for pre-stroke screening. 
From the above-mentioned, the indirect cost of stroke, particularly premature mortality along with lost productivity, is therefore much greater than the sum of all direct costs of stroke [15]. Unfortunately these staggering numbers only reflect the economical burden of stroke, while the costs borne by patients and their family, as well as the cost of comorbidity is not even cited [16]. Since primary stroke represents almost $80 \%$ of all stroke events, the main focus should therefore be on more effective prevention strategies to bridle the future escalation in stroke incidence and resulting disability $[10,17]$

\section{Current approach: Diagnostic testing and preventative strategies}

Currently various diagnostic tests are employed to determine the specific type of ischemic stroke as classified by the TOAST criteria [18-22]. These tests are, however, after the stroke and only contribute to the unquestionably crucial aspect of treating that particular stroke patient, but it does not improve prevention of future events. Prevention strategies regarding first-time stroke need urgent attention given the alarming present and future incidence of stroke. Figure 2 shows a comparison of current diagnostic and preventative measures.

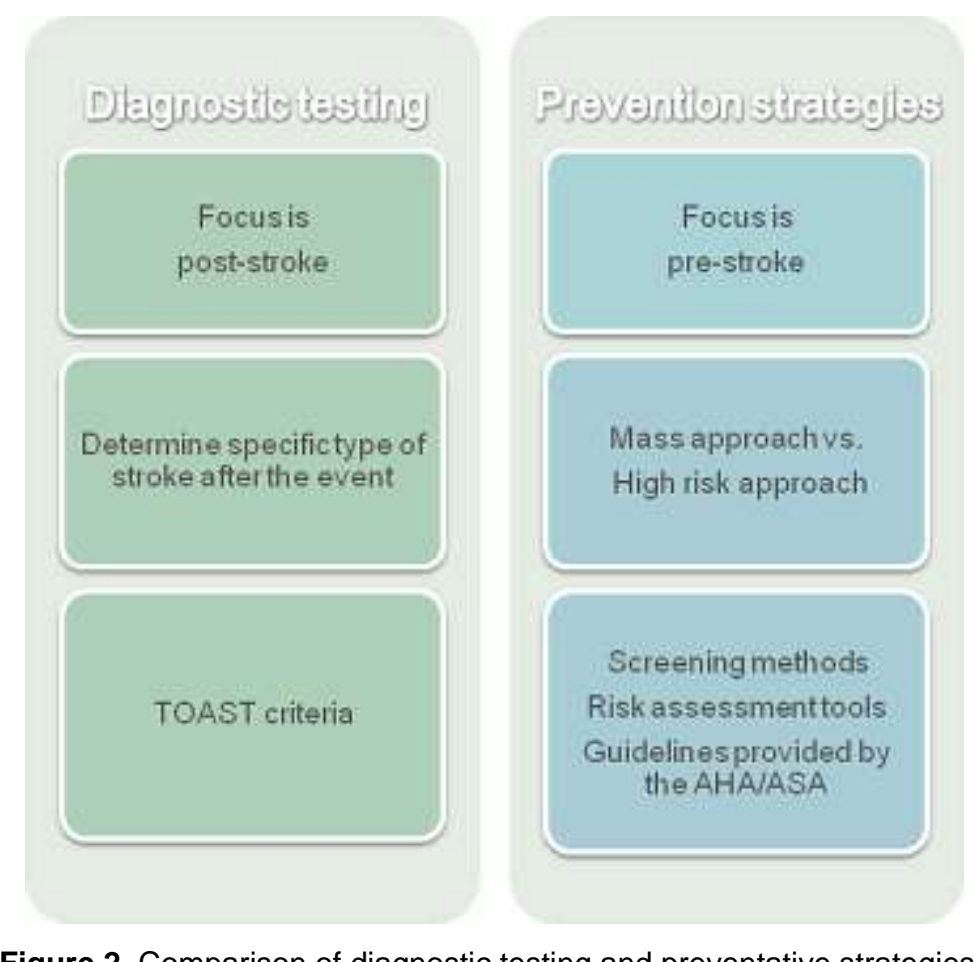

Figure 2. Comparison of diagnostic testing and preventative strategies.

With regards to prevention strategies, two core approaches are currently followed namely the 'mass' approach and then the 'high risk' approach. The first focuses on decreasing the risk factor exposure of a population while the latter concentrate on identification of specific 
individuals at risk of stroke and subsequent modification or treatment of their particular risk profile [17]. Although the NIH has recently started focusing on the 'high risk' approach of individualized patient-centered precision medicine [23], the 'mass' approach specifically the two population-based intervention strategies of reducing salt intake and controlling tobacco, has had a positive effect on chronic disease prevention [24].

Different screening methods have been established over the past few years including community stroke screening [25] and ECG iPhone technology to screen for specifically atrial fibrillation, a major risk factor for stroke [26]. Risk assessment tools (including QStroke [27], FSRS [28] and the Stroke Riskometer $\mathrm{App}^{\mathrm{TM}}$ [17]) are useful in the identification of individuals in need of therapeutic intervention or who may not be treated due to the presence of only 1 risk factor. It is also a practical tool to alert clinicians as well as patients of possible risk [29]. Although these tools can be used to predict stroke, they revolve around the input of risk factors and thus excludes other types of testing (specifically blood biomarkers) and subsequently individuals who are at risk of suffering a stroke due to other factors like coagulopathies, which do not form part of the traditional risk factors, will potentially fall through the cracks. Although prevention strategies utilizing a risk assessment tool are beneficial to individuals with primarily high-risk profiles, it is the group of people with mildly increased risk that show the highest number of stroke incidence [30, 31].

In 2014 Meschia and coworkers published a very useful collection of guidelines pertaining to the primary prevention of stroke [29]. This statement served as an update of the report done by Sacco and coworkers in 2006 [32]. Both these reports provide comprehensive and evidence-based recommendations for the prevention of first time stroke and transient ischemic attack. Table 1 provides a summary of the risk factors identified in 2014 [29] where screening is suggested.

Table 1: Recommendations with regards to screening protocols for specific risk factors.

\begin{tabular}{|c|l|}
\hline Risk factor & \multicolumn{1}{|c|}{ Recommendation regarding screening } \\
\hline Genetic Factors & $\begin{array}{l}\text { Family history may identify individuals at risk but genetic screening of } \\
\text { general public for prevention of a first stroke not recommended }\end{array}$ \\
\hline Hypertension & $\begin{array}{l}\text { Regular BP screening and the appropriate treatment of patients with } \\
\text { hypertension are recommended. } \\
\text { Annual screening for high BP and health-promoting lifestyle modification } \\
\text { are recommended for patients with pre-hypertension. }\end{array}$ \\
\hline Atrial fibrillation (AF) & Active screening for AF in patients $>65$ years of age can be useful \\
\hline Sickle cell anemia disease (SCD) & $\begin{array}{l}\text { Transcranial doppler ultrasonography screening for children with SCD } \\
\text { starting at 2 years of age and continuing annually to 16 years of age }\end{array}$ \\
\hline HYPERCOAGULABILITY* & $\begin{array}{l}\text { Genetic screening for detection of inherited hypercoagulable states or } \\
\text { patients with or acquired thrombophilia, as possible risk factor is not well } \\
\text { established }\end{array}$ \\
\hline
\end{tabular}


Thrombosis plays a critical role in the pathophysiology of stroke. Ischemic stroke has two main aetiologies: firstly carotid atherosclerotic plaque rupture and superimposed thrombus formation (contributing to about $70-80 \%$ of cases) and secondly systemic embolism of a cardiac thrombus (contributing to about $30 \%$ of cases, most common in AF patients)[33].

Atherosclerosis can be either an extended process of slow luminal narrowing (which is the "classic" concept) of a rapid process that leads to luminal obstruction (which involves plaque hemorrhage with luminal thrombosis, healing of the plaque and incorporation of the thrombus into the coronary plaque, therefore lumen narrowing and increased plaque burden).

It is troubling to note that a specific protocol of screening for hypercoagulability or necessity thereof is not established. Especially since a significant number of ischemic stroke events in younger individuals, whom exhibit none of the common arteriosclerotic risk factors, are triggered by coagulopathies (either genetic or acquired) or other coagulation defects of undetermined etiology [34]. It is clear that clinical research mainly focuses on post-stroke resulting in an overemphasis on clinical parameters after the event and less emphasis on diagnosis of a possible thrombotic event.

\section{A new approach: a comprehensive methodology for pre-stroke screening}

We therefore propose a comprehensive approach that will, in the long run, decrease the financial burden and prevent thrombotic event (stroke). This approach is needed because stroke is a complicated disease with many factors contributing to the development of stroke, including metabolic syndrome and both acquired and non-acquired risk factors.

Hypercoagulability, inflammation and infection are some of the potentially modifiable risk factors that are less well-documented [13]. Chronic inflammatory disease is associated with increased stroke risk and measurement of some inflammatory markers like hs-CRP or lipoprotein-associated phospholipase A2 in patients without cardiovascular disease may be useful in identifying individuals at risk of stroke [29]. The overarching element is therefore systemic inflammation leading to "systemic" hypercoagulability and central to this is the involvement of hyper-activated platelets, hypercoagulable fibrin and eryptotic and necrotic erythrocytes. Another well-established factor is the involvement or increased iron levels in inflammation.

The relation between iron, inflammation and hypercoagulability is well established [35-38] specifically the effect of iron on blood coagulation [39-50]. Changes to these structures might be used as "new" parameters in a screening protocol. 
This novel screening protocol will have a comprehensive methodology with an individualized patient-centered precision medicine approach [23]. Precision medicine takes individual variability into account when treatment and preventative measures are considered for a patient [23]. The proposed outline for this approach model is shown in Figure 3.
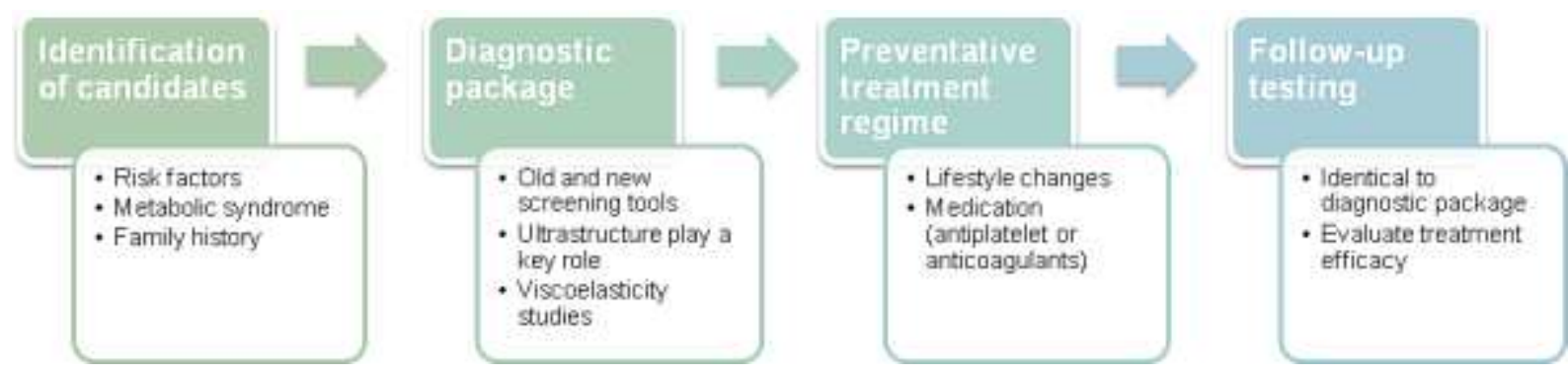

Figure 3. An outline of the suggested method for a screening protocol that incorporates old and new methods such as ultrastructural and viscoelasticity studies to prevent stroke.

A typical process will have four steps. The first step will be identification of candidates through a questionnaire or as recommended by a clinician. Included will be individuals with a family history, with the typical risk factors of stroke or that suffer from metabolic syndrome and/or other diseases that are associated with chronic inflammation.

Secondly a diagnostic package, which includes old and new screening tools, will be used to identify the person's risk of stroke. Here we suggest that ultrastructural tests, specifically scanning electron microscopy (SEM), together with traditional methods may possibly be the answer to preventative and individualized patient-centered precision medicine approach [23]. SEM is a very precise method and complements other methods like thromboelastography (TEG). Rosenson's team has established the importance of measuring blood rheology and viscosity [51, 52]. SEM has been used extensively to establish the exact morphological characteristics of platelets, fibrin networks and erythrocytes from healthy individuals as well as individuals who suffered a TEI stroke [53-58]. Figure 4 shows the typical platelet $(A)$, fibrin network (B) and erythrocyte morphology (C) of a healthy individual and figure 5 shows the typical platelet, fibrin network and erythrocyte morphology of a person who suffered a TEI stroke. 

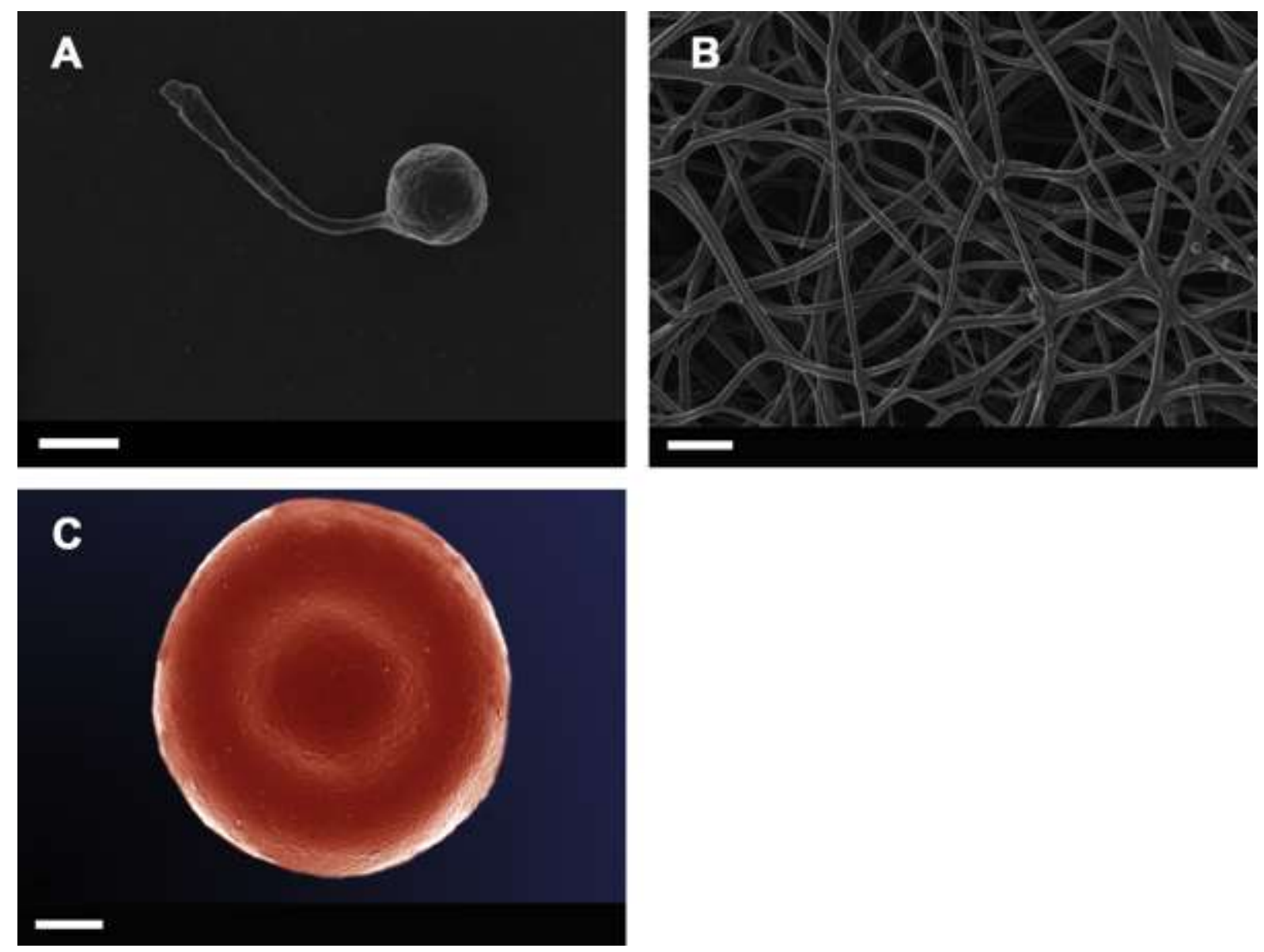

Figure 4. Healthy platelet (A), fibrin network (created by adding thrombin to plasma) (B) and erythrocyte (C). Erythrocytes have smooth membranes and are typically discoid in shape. Scale: $1 \mu \mathrm{m}$.
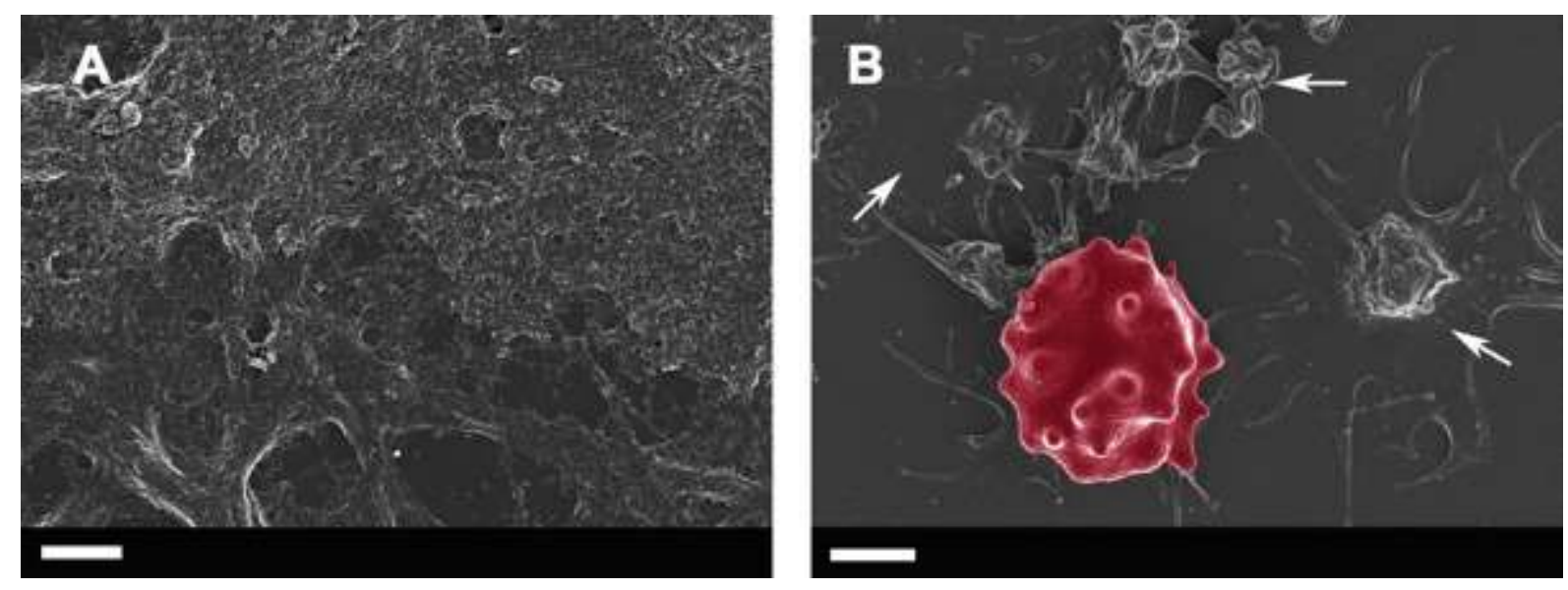

Figure 5. Typical matted, hypercoagulable fibrin fiber mat in thromboembolic ischemic stroke (A) and structurally changed erythrocyte with hyperactivated platelets as seen in a typical whole blood smear (B). Arrows show spreaded, hyper-activated platelets in close contact with an eryptotic erythrocyte. Scale: $1 \mu \mathrm{m}$.

Since platelets play such a crucial role in the early stages of thrombus formation they form an integral part of morphological studies associated with stroke [59]. Platelets are also closely involved in atherosclerotic inflammatory response, thrombotic vascular occlusion, 
formation of micro-embolisms and vasoconstriction along with plaque progression. If platelet activation persists it can have dire consequences for patients with acute coronary syndrome (ACS) increasing their risk for ischemic events and subacute stent thrombosis [60].

SEM and TEM analysis of platelet morphology have been deemed essential systemic tools in understanding neurodegenerative and other disease pathogenesis [61,62]. Platelets from TEI stroke patients are swollen and their taut membranes are characteristic of necrosis [54]. When fibrin networks are prepared thick dense matted deposits (DMDs) are formed [57]. This altered morphology is suggested to be present long before the actual thrombotic event [63]. Erythrocytes from TEI stroke patients show elongated membrane extensions that directly interacted with DMDs of fibrin fibers. Since other thrombotic diseases like diabetes [40] that precede stroke are also associated with this specific type of interaction between erythrocytes and fibrin it suggests that this interaction is the trigger rather than the consequence of the stroke [55]. The diagnostic package will thus indicate whether an individual has a healthy clotting profile or need preventative treatment.

If an individual is deemed at risk of stroke according to their clotting profile, the third step will be a preventative treatment regime. This will include for example lifestyle changes and medication that reduce BP and LDL-C, target HDL [64] and antiplatelet agents, which have been shown to prevent stroke [29, 32, 65]. Antithrombotic therapy is the cornerstone of stroke treatment and prevention, therefore the CHADS2 score can be used to determine the specific type of antiplatelet or antithrombotic treatment do be used for each individual [33]. The treatment regime will be tailor-made for each individual, depending on the results from the diagnostic package.

Lastly the patient will undergo follow-up testing with the same techniques as used in the diagnostic package. This is in line with a comprehensive approach as well as an individualized patient-centered precision medicine approach as suggested by the NIH [23]. In the long run this preventative approach will alleviate the financial burden associated with stroke, since the cost of hospitalisation and medical care post-stroke will be eliminated if stroke is prevented. Preventing stroke will also decrease the economic burden of stroke by early detection thereby preserving the health of the working class, especially the age group 45-64 years which are foreseen to suffer the greatest number of strokes. Quality of life does not bear a price tag; stroke prevention will not only decrease mortality but also decrease chronic disability synonym with post-stroke. 


\section{Conclusion}

It is reasonable to implement preventative health service programs to aid in the methodical identification and treatment of risk factors in every person demonstrating a risk at stroke [29]. Preventative strategies are essential for decreasing stroke incidence, especially with the increasing incidence of metabolic syndrome and its associated complications [66]. I quote Geoffrey Rose: "Why is so large a part of our research devoted to the "mechanics of dying", and so little to the scientific, social and economic basis of prevention? [67]"

We already postulated in 2011 that scanning electron microscopy should be used as a screening regime in the identification of possible stroke as well as monitoring progress of stroke patients during and after treatment [57]. Ultrastructural tests, particularly scanning electron microscopy, provide an innovative and novel advance in preventative and individualized patient-centered precision medicine. This precise technique when used in combination with well-established methods as well as new methods like TEG, as a screening tool to prevent stroke can ultimately alleviate the financial and economical burden of TEI stroke and also improve quality of life. Although we appreciate the fact that this suggestion might be difficult to accept by clinicians, a bold new approach is needed to address this pandemic we call stroke.

\section{Ethical considerations}

Ethical clearance was obtained from the University of Pretoria Human Ethics Committee for the use of blood from thrombo-embolic ischemic stroke patients and healthy volunteers. All participants filled in informed consent forms.

\section{Funding}

Funding: NRF and MRC of South Africa: E Pretorius.

\section{Conflict of Interest statement}

There are no conflicts of interest to declare by any of the authors. 


\section{References}

[1] Ovbiagele B, Nguyen-Huynh MN. Stroke Epidemiology: Advancing Our Understanding of Disease Mechanism and Therapy. Neurotherapeutics. 2011;8:319-29.

[2] Mozaffarian D, Benjamin EJ, Go AS, Arnett DK, Blaha MJ, Cushman M, et al. Heart disease and stroke statistics-2015 update: a report from the american heart association. Circulation. 2015;131:e29.

[3] Feigin VL, Forouzanfar MH, Krishnamurthi R, Mensah GA, Connor M, Bennett DA, et al. Global and regional burden of stroke during 1990-2010: findings from the Global Burden of Disease Study 2010. The Lancet. 2014;383:245-55.

[4] Mozaffarian D, Benjamin EJ, Go AS, Arnett DK, Blaha MJ, Cushman M, et al. Executive summary: heart disease and stroke statistics-2015 update: a report from the american heart association. Circulation. 2015;131:434.

[5] Roger VL, Go AS, Lloyd-Jones DM, Adams RJ, Berry JD, Brown TM, et al. Heart disease and stroke statistics-2011 update a report from the American Heart Association. Circulation. 2011;123:e18-e209.

[6] Ovbiagele B, Goldstein LB, Higashida RT, Howard VJ, Johnston SC, Khavjou OA, et al. Forecasting the Future of Stroke in the United States: A Policy Statement From the American Heart Association and American Stroke Association. Stroke. 2013;44:2361-75.

[7] Strong K, Mathers C, Bonita R. Preventing stroke: saving lives around the world. The Lancet Neurology. 2007;6:182-7.

[8] Mukherjee D, Patil CG. Epidemiology and the global burden of stroke. World neurosurgery. 2011;76:S85-S90.

[9] Association AH. Heart disease and stroke statistics-2004 update. Dallas, Texas: American Heart Association, 2003. 2004.

[10] Go AS, Mozaffarian D, Roger VL, Benjamin EJ, Berry JD, Blaha MJ, et al. Heart Disease and Stroke Statistics-2014 Update: A Report From the American Heart Association. Circulation. 2014;129:e28-e292.

[11] Donnan GA, Fisher M, Macleod M, Davis SM. Stroke. Lancet. 2008;371:1612-23.

[12] Lopez AD, Mathers CD, Ezzati M, Jamison DT, Murray CJ. Global and regional burden of disease and risk factors, 2001: systematic analysis of population health data. Lancet. 2006;367:174757.

[13] Goldstein LB, Adams R, Alberts MJ, Appel LJ, Brass LM, Bushnell CD, et al. Primary Prevention of Ischemic Stroke: A Guideline From the American Heart Association/American Stroke Association Stroke Council: Cosponsored by the Atherosclerotic Peripheral Vascular Disease Interdisciplinary Working Group; Cardiovascular Nursing Council; Clinical Cardiology Council; Nutrition, Physical Activity, and Metabolism Council; and the Quality of Care and Outcomes Research Interdisciplinary Working Group: The American Academy of Neurology affirms the value of this guideline. Stroke. 2006;37:1583-633.

[14] Olesen J, Gustavsson A, Svensson M, Wittchen HU, Jönsson B. The economic cost of brain disorders in Europe. European Journal of Neurology. 2012;19:155-62. 
[15] Demaerschalk BM, Hwang H-M, Leung G. US cost burden of ischemic stroke: a systematic literature review. The American journal of managed care. 2010;16:525-33.

[16] Evers SMAA, Struijs JN, Ament AJHA, van Genugten MLL, Jager JC, van den Bos GAM. International Comparison of Stroke Cost Studies. Stroke. 2004;35:1209-15.

[17] Parmar P, Krishnamurthi R, Ikram MA, Hofman A, Mirza SS, Varakin Y, et al. The Stroke Riskometer ${ }^{\mathrm{TM}}$ App: Validation of a data collection tool and stroke risk predictor. International Journal of Stroke. 2015;10:231.

[18] Alvarez-Perez FJ, Castelo-Branco M, Alvarez-Sabin J. Usefulness of measurement of fibrinogen, D-dimer, D-dimer/fibrinogen ratio, C reactive protein and erythrocyte sedimentation rate to assess the pathophysiology and mechanism of ischaemic stroke. Journal of Neurology, Neurosurgery \& Psychiatry. 2011;82:986-92.

[19] Hanson E, Jood K, Karlsson S, Nilsson S, Blomstrand C, Jern C. Plasma levels of von Willebrand factor in the etiologic subtypes of ischemic stroke. Journal of Thrombosis and Haemostasis. 2011;9:275-81.

[20] Liu L-B, Li M, Zhuo W-Y, Zhang Y-S, Xu A-D. The Role of Hs-CRP, D-Dimer and Fibrinogen in Differentiating Etiological Subtypes of Ischemic Stroke. PLoS ONE. 2015;10:e0118301.

[21] Montaner J, Perea-Gainza M, Delgado P, Ribó M, Chacón P, Rosell A, et al. Etiologic Diagnosis of Ischemic Stroke Subtypes With Plasma Biomarkers. Stroke. 2008;39:2280-7.

[22] Renjen P, Beg M, Ahmad K. Epidemiological study of incidence and risk factors of Ischemic stroke subtypes according to Trial of ORG 10172 in acute stroke treatment criteria: A 3 years, hospital-based study2015.

[23] Collins FS, Varmus H. A New Initiative on Precision Medicine. New England Journal of Medicine. 2015;372:793-5.

[24] Asaria P, Chisholm D, Mathers C, Ezzati M, Beaglehole R. Chronic disease prevention: health effects and financial costs of strategies to reduce salt intake and control tobacco use. The Lancet.370:2044-53.

[25] DeLemos CD, Atkinson RP, Croopnick SL, Wentworth DA, Akins PT. How effective are "community" stroke screening programs at improving stroke knowledge and prevention practices? Results of a 3-month follow-up study. Stroke. 2003;34:e247-e9.

[26] Lowres N, Neubeck L, Salkeld G, Krass I, McLachlan AJ, Redfern J, et al. Feasibility and costeffectiveness of stroke prevention through community screening for atrial fibrillation using iPhone ECG in pharmacies. The SEARCH-AF study. Thromb Haemost. 2014;111:1167-76.

[27] Hippisley-Cox J, Coupland C, Brindle P. Derivation and validation of QStroke score for predicting risk of ischaemic stroke in primary care and comparison with other risk scores: a prospective open cohort study. Bmj. 2013;346.

[28] Wolf PA, D'Agostino RB, Belanger AJ, Kannel WB. Probability of stroke: a risk profile from the Framingham Study. Stroke. 1991;22:312-8.

[29] Meschia JF, Bushnell C, Boden-Albala B, Braun LT, Bravata DM, Chaturvedi S, et al. Guidelines for the Primary Prevention of Stroke: A Statement for Healthcare Professionals From the American Heart Association/American Stroke Association. Stroke. 2014;45:3754-832. 
[30] Rose G. The strategy of preventive medicine. The strategy of preventive medicine. 1992.

[31] Rose G. Sick individuals and sick populations. International journal of epidemiology. 2001;30:427-32.

[32] Sacco RL, Adams R, Albers G, Alberts MJ, Benavente O, Furie K, et al. Guidelines for Prevention of Stroke in Patients With Ischemic Stroke or Transient Ischemic Attack A Statement for Healthcare Professionals From the American Heart Association/American Stroke Association Council on Stroke: Co-Sponsored by the Council on Cardiovascular Radiology and Intervention: The American Academy of Neurology affirms the value of this guideline. Circulation. 2006;113:e409-e49.

[33] Santos-Gallego CG, Bayon J, Badimon JJ. Thrombi of different pathologies: implications for diagnosis and treatment. Curr Treat Options Cardiovasc Med. 2010;12:274-91.

[34] Weih M, Villringer A. Coagulopathies in Ischemic Stroke. Stroke. 2001;32:1234-7.

[35] Kell DB. Iron behaving badly: inappropriate iron chelation as a major contributor to the aetiology of vascular and other progressive inflammatory and degenerative diseases. BMC medical genomics. 2009;2:2.

[36] Kell DB, Pretorius E. Serum ferritin is an important inflammatory disease marker, as it is mainly a leakage product from damaged cells. Metallomics. 2014;DOI: 10.1039/c3mt00347g.

[37] Kell DB, Pretorius E. The simultaneous occurrence of both hypercoagulability and hypofibrinolysis in blood and serum during systemic inflammation, and the roles of iron and fibrin (ogen). Integrative Biology. 2015;7:24-52.

[38] Pretorius E, Kell DB. Diagnostic morphology: biophysical indicators for iron-driven inflammatory diseases. Integrative Biology. 2014.

[39] Lipinski B, Pretorius E. Hydroxyl radical-modified fibrinogen as a marker of thrombosis: the role of iron. Hematology. 2012;17:241-7.

[40] Lipinski B, Pretorius E. Novel pathway of ironinduced blood coagulation: implications for diabetes mellitus and its complications. Polskie Archiwum Medycyny Wewnetrznej. 2012;122:115-22.

[41] Lipinski B, Pretorius E. Iron-Induced Fibrin in Cardiovascular Disease. Current neurovascular research. 2013.

[42] Lipinski B, Pretorius E. The role of iron-induced fibrin in the pathogenesis of Alzheimer's disease and the protective role of magnesium. Frontiers in human neuroscience. 2013;7.

[43] Lipinski B, Pretorius E, Oberholzer HM, van der Spuy WJ. Interaction of fibrin with red blood cells: the role of iron. Ultrastruct Pathol. 2012;36:79-84.

[44] Lipinski B, Pretorius E, Oberholzer HM, Van Der Spuy WJ. Iron enhances generation of fibrin fibers in human blood: Implications for pathogenesis of stroke. Microsc Res Tech. 2012;75:1185-90.

[45] Pretorius E, Bester J, Vermeulen N, Lipinski B. Oxidation inhibits iron-induced blood coagulation. Curr Drug Targets. 2013;14:13-9.

[46] Pretorius E, Bester J, Vermeulen N, Lipinski B, Gericke GS, Kell DB. Profound Morphological Changes in the Erythrocytes and Fibrin Networks of Patients with Hemochromatosis or with Hyperferritinemia, and Their Normalization by Iron Chelators and Other Agents. PLoS ONE. 2014;9:e85271. 
[47] Pretorius E, Lipinski B. Differences in Morphology of Fibrin Clots Induced with Thrombin and Ferric lons and Its Pathophysiological Consequences. Heart, lung \& circulation. 2012.

[48] Pretorius E, Lipinski B. Iron alters red blood cell morphology. Blood. 2013;121:9.

[49] Pretorius E, Vermeulen N, Bester J, Lipinski B. Novel use of scanning electron microscopy for detection of iron-induced morphological changes in human blood. Microsc Res Tech. 2013;76:268-71. [50] Pretorius E, Vermeulen N, Bester J, Lipinski B, Kell DB. A novel method for assessing the role of iron and its functional chelation in fibrin fibril formation: the use of scanning electron microscopy. Toxicology mechanisms and methods. 2013;23:352-9.

[51] Lee SR, Jung JM, Jung LY, Lee JH, Lee SH, Rhee KS, et al. Elevated coronary whole blood viscosity in acute coronary syndrome patients. Clin Hemorheol Microcirc. 2013;55:85-94.

[52] Jeong SK, Rosenson RS. Shear rate specific blood viscosity and shear stress of carotid artery duplex ultrasonography in patients with lacunar infarction. BMC neurology. 2013;13:36.

[53] Du Plooy JN, Buys A, Duim W, Pretorius E. Comparison of Platelet Ultrastructure and Elastic Properties in Thrombo-Embolic Ischemic Stroke and Smoking Using Atomic Force and Scanning Electron Microscopy. PLoS ONE. 2013;8:e69774.

[54] Pretorius E, Engelbrecht MJ, Duim W. Thromboembolic ischemic stroke and the presence of necrotic platelets: a scanning electron microscopy investigation. Ultrastruct Pathol. 2012;36:19-22.

[55] Pretorius E, Lipinski B. Thromboembolic ischemic stroke changes red blood cell morphology. Cardiovascular pathology : the official journal of the Society for Cardiovascular Pathology. 2013;22:241-2.

[56] Pretorius E, Steyn H, Engelbrecht M, Swanepoel AC, Oberholzer HM. Differences in fibrin fiber diameters in healthy individuals and thromboembolic ischemic stroke patients. Blood coagulation \& fibrinolysis : an international journal in haemostasis and thrombosis. 2011;22:696-700.

[57] Pretorius E, Swanepoel AC, Oberholzer HM, Van Der Spuy WJ, Duim W, Wessels PF. A descriptive investigation of the ultrastructure of fibrin networks in thrombo-embolic ischemic stroke. Journal of Thrombosis and Thrombolysis. 2011;31:507-13.

[58] Swanepoel AC, Pretorius E. Scanning electron microscopy analysis of erythrocytes in thromboembolic ischemic stroke. International journal of laboratory hematology. 2012;34:185-91.

[59] Santos-Gallego CG, Badimon JJ. The Sum of Two Evils: Pneumonia and Myocardial Infarction: Is Platelet Activation the Missing Link?*. Journal of the American College of Cardiology. 2014;64:19268.

[60] Braunwald E, Angiolillo D, Bates E, Berger PB, Bhatt D, Cannon CP, et al. The problem of persistent platelet activation in acute coronary syndromes and following percutaneous coronary intervention. Clin Cardiol. 2008;31:117-20.

[61] Shrivastava M, Vivekanandhan S. An insight into ultrastructural and morphological alterations of platelets in neurodegenerative diseases. Ultrastruct Pathol. 2011;35:110-6.

[62] Shrivastava M, Das TK, Behari M, Pati U, Vivekanandhan S. Ultrastructural variations in platelets and platelet mitochondria: a novel feature in amyotrophic lateral sclerosis. Ultrastruct Pathol. 2011;35:52-9. 
[63] Undas A, Slowik A, Wolkow P, Szczudlik A, Tracz W. Fibrin clot properties in acute ischemic stroke: relation to neurological deficit. Thromb Res. 2010;125:357-61.

[64] Santos-Gallego CG, Badimon JJ, Rosenson RS. Beginning to understand high-density lipoproteins. Endocrinol Metab Clin North Am. 2014;43:913-47.

[65] Adams RJ, Albers G, Alberts MJ, Benavente O, Furie K, Goldstein LB, et al. Update to the AHA/ASA Recommendations for the Prevention of Stroke in Patients With Stroke and Transient Ischemic Attack. Stroke. 2008;39:1647-52.

[66] Cooney M-T, Dudina A, Whincup P, Capewell S, Menotti A, Jousilahti P, et al. Re-evaluating the Rose approach: comparative benefits of the population and high-risk preventive strategies. European Journal of Cardiovascular Prevention \& Rehabilitation. 2009;16:541-9.

[67] Rose G. Strategy of prevention: lessons from cardiovascular disease. British medical journal (Clinical research ed). 1981;282:1847-51. 